\title{
PENGARUH E-SERVICE QUALITY TERHADAP CUSTOMER LOYALTY MELALUI CUSTOMER SATISFACTION PADA TOKO ON LINE BUKA LAPAK
}

\author{
Ahmad Irwansyah, Riko Mappadeceng \\ Dosen Fakultas Ekonomi Universitas Batanghari \\ iwan21jmb@gmail.com
}

\begin{abstract}
Along with the development of an increasingly modern era, information technology is growing very rapidly. This is because all information required can be obtained easily and quickly via the internet. The development of the internet today not only serves as a medium of information, but the internet can also be utilized for the benefit of the business as a business online using a service-based website. The website-based services in many of the important components in it to achieve success in business, one of which is the quality of service (EService Quality). The company provides e-service quality the higher the customer then it will give rise to customer satisfaction, and in a long period of time will certainly generate customer loyalty. E-service quality is defined as the assessment and evaluation of the quality of the overall service delivery to consumers in a virtual market. Word of satisfaction or satisfaction derived from the Latin "satis" which means good enough, sufficient, and "facio" which means do or make. Contentment is a feeling happy or disappointed someone arising due to compare performance percepted products or results against the expectations of the customer. Customer loyalty or customer loyalty is the commitment of customers to a brand, stores or suppliers based on a very positive trait purchase in the long run. Buka Lapak is one of the shop on line which is currently enough many have customers in Indonesia. Although the Buka Lapak already quite well-established as retailers on line but with a growing number of online stores are popping up then the Buka Lapak need to keep on doing the evaluation in order to remain able to compete with any other online store. From the analysis results can be summed up as that of E-service quality effect directly against customer loyalty, consumers Buka Lapak Indonesia, E-service quality positive effect towards customer satisfaction of consumers Buka Lapak, Indonesia E-service quality to customer loyalty through the customer satisfaction of consumers Buka Lapak Indonesia.
\end{abstract}

Keyword: E-Service Quality, Customer Satisfaction, Customer Loyalty.

\section{PENDAHULUAN}

Seiring dengan perkembangan jaman yang semakin modern, teknologi informasi berkembang sangat pesat. Hal ini dikarenakan seluruh informasi yang dibutuhkan dapat diperoleh dengan mudah dan cepat melalui fasilitas internet. Tingkat populasi pengguna internet di dunia dan khususnya Indonesia meningkat drastis dalam beberapa tahun terakhir. Perkembangan internet saat ini bukan hanya berfungsi sebagai media informasi, namun internet juga dapat dimanfaatkan untuk kepentingan bisnis yaitu sebagai bisnis online dengan menggunakan layanan berbasis website (Situmorang, 2012). Dalam layanan berbasis website tersebut banyak komponen-komponen penting didalamnya untuk mencapai kesuksesan dalam bisnis, salah satunya adalah kualitas pelayanan (E-Service Quality). Perusahaan yang memberikan e-service quality semakin tinggi kepada pelanggan maka akan menimbulkan customer satisfaction, dan dalam jangka waktu yang panjang tentunya akan menghasilkan customer loyalty.

Pertumbuhan pengguna internet yang semakin besar tiap tahunnya dapat dimanfaatkan untuk kepentingan bisnis. Internet telah dianggap sebagai alat untuk meningkatkan kinerja bisnis dan meningkatkan nilai yang dirasakan konsumen (Levenburg, 2005). Pemanfaatan internet oleh ritel online adalah sebagai perantara transaksi jual-beli suatu produk ataupun jasa dengan dukungan sistem dan jaringan komputer. Istilah yang muncul kemudian adalah Electronic commerce (e-commerce) adalah suatu kegiatan pertukaran informasi, data dan nilai antara dua atau lebih kelompok dengan menggunakan sistem komputer dan jaringan internet (Prashad, 2000). E-Commerce di Indonesia terus berkembang pesat seiring dengan kemajuan teknologi, komunikasi dan kesadaran masyarakat untuk mencari suasana belanja baru di dunia internet. Toko/ritel online semakin bermunculan, baik dalam negeri maupun luar negeri. Di tengah tumbuhnya pasar online di Indonesia, untuk dapat unggul dalam persaingan setiap ritel online dituntut untuk dapat memberikan kepuasan yang maksimal kepada konsumen, dimana kepuasan konsumen akan memiliki pengaruh terhadap 
loyalitas konsumen itu sendiri. Untuk itu, perusahaan perlu mengukur persepsi kualitas pelayanan elektronik (E-service quality), sebab website merupakan medium utama konsumen dalam melakukan aktivitas belanja dan transaksi menggantikan peran penjual. Buka Lapak merupakan salah satu toko on line yang saat ini cukup banyak memiliki pelanggan di Indonesia. Meskipun Buka Lapak sudah cukup mapan sebagai peritel on line akan tetapi dengan semakin banyaknya toko online yang bermunculan maka Buka Lapak perlu terus melakukan evaluasi agar tetap mampu bersaing dengan toko online yang lain. Selama ini Buka Lapak sudah berusaha memberikan pelayanan yang baik akan tetapi masih banyak yang perlu dibenahi, karena customer satisfaction akan terpenuhi melalui penawaran kualitas yang tinggi (Salameh \& Hasan, 2015), dimana dengan e-service quality yang tinggi, kebutuhan pelanggan dapat terpenuhi. Berdasarkan latar belakang diatas maka penelitian ini akan melakukan identifikasi pengaruh e-service quality terhadap customer loyalty melalui customer satisfaction studi pada konsumen Buka Lapak Indonesia.

\section{Tinjauan Pustaka \\ E-Service Quality}

E-service quality didefinisikan sebagai penilaian dan evaluasi secara menyeluruh terhadap kualitas pengantaran pelayanan kepada konsumen dalam pasar virtual (Santos, 2003). Zeithaml et al. (2000) mendefinisikan e-service quality merupakan keseluruhan interaksi yang terjadi antara konsumen dengan website, dimana website memberikan kenyamanan dan keefektifan dalam berbelanja, membeli dan mengantarkan produknya ke konsumen. Dalam e-service konsumen tidak mengevaluasi masing-masing subproses ditiap kunjungan online tetapi keseluruhan proses yang dilaluinya untuk memperoleh layanan. Service quality pada lingkungan online menjadi sesuatu yang penting dalam penentuan kesuksesan atau kegagalan dari perdagangan elektronik.Jeong dan Lee (2010) mendefinisikan layanan dalam lingkungan elektronik $(e-$ service) sebagai "the delivery as service using new media such as the web". Definisi tersebut berarti penyerahan jasa dengan menggunakan media baru yaitu web. Keberadaan bukti dari kualitas layanan atas penyerahan melalui website merupakan kesuksesan strategi yang sangat penting dibandingkan dengan harga murah dan keberadaan web (Zeithaml dan Bitner, 2006).

Lee dan Lin (2005) menjelaskan e-service quality sebagai evaluasi customer secara keseluruhan serta penilaian terhadap kualitas dari pelayanan pengiriman dalam virtual marketplace.Penelitian selama dua dekade terakhir banyak mendemonstrasikan bahwa service quality mempengaruhi keputusan pembelian, namun hanya beberapa temuan saja yang diterapkan kedalam bidang e-commerce.Oleh karena itu, online customer mengharapkan tingkat kualitas pelayanan yang setara atau bahkan lebih tinggi daripada traditional customer.

\section{Customer Satisfaction}

Kata kepuasan atau satisfaction berasal dari bahasa Latin "satis" yang berarti cukup baik, memadai, dan "facio" yang berarti melakukan atau membuat. Menurut Kotler dan Keller (2006), kepuasan adalah perasaan senang atau kecewa seseorang yang timbul karena membandingkan kinerja yang dipresepsikan produk atau hasil terhadap ekspektasi pelanggan. Apabila kinerja berada di atas persepsi pelanggan, maka pelanggan akan sangat puas dan demikian pula sebaliknya apabila kinerja yang ada berada di bawah ekspektasi pelanggan, maka pelanggan akan kecewa. Hal tersebut ditambahkan kembali oleh Kotler dan Keller (2006) yaitu pelanggan yang sangat puas biasanya akan tetap setia untuk waktu yang lebih lama, membeli lagi ketika perusahaan memperkenalkan produk baru dan memperbaharui produk yang lama, membicarakan hal-hal baik tentang perusahaan dan produknya kepada orang lain dan tidak terlalu sensitif terhadap harga. Sebaliknya apabila pelanggan kecewa dapat membawa dampak negatif bagi perusahaan yaitu menurunkan jumlah pelanggan karena pelanggan tidak tertarik lagi untuk menggunakan jasa maupun produk suatu perusahaan sehingga akan berdampak pada penurunan laba. Terdapat fakta bahwa lebih baik mempertahankan pelanggan yang ada daripada harus menarik pelanggan baru karena hal tersebut akan menjadi salah satu pemicu perusahaan untuk meningkatkan perhatian kepada kepuasan pelanggan (Fornell \& Wenerfelt, 1987). Pengertian lain mengenai kepuasan pelanggan dikemukakan oleh Tjiptono (2004) menyatakan bahwa kepuasan pelanggan merupakan evaluasi purna beli dimana alternative yang dipilih sekurang-kurangnya sama atau melampaui harapan pelanggan, sedangkan ketidakpuasan timbul apabila hasil / outcome tidak memenuhi harapan. Pada intinya kepuasan pelanggan merupakan perbedaan antara tingkat kepentingan kinerja atau hasil 
yang dirasakan dibandingkan dengan persepsi pelanggan. Dari berbagai pendapat yang dikemukakan para ahli bisa disimpulkan kepuasan pelanggan adalah hasil evaluasi purna beli dari pelanggan dimana produk atau jasa yang dikonsumsi sekurang-kurangnya dapat memberikan hasil sama ataupun melebihi harapan pelanggan, sedangkan ketidakpuasan terjadi saat hasil yang diperoleh tidak memenuhi harapan pelanggan. (Adisetiawan, 2013)

\section{Customer Loyalty}

Customer loyalty atau loyalitas pelanggan adalah komitmen pelanggan terhadap suatu merek, toko atau pemasok berdasarkan sifat yang sangat positif dalam pembelian jangka panjang (Tjiptono, 2000). Huretal dalam Siagian dan Cahyono (2014) mengatakan bahwa loyalitas pelanggan didefinisikan sebagai komitmen yang dipegang teguh untuk membeli kembali produk pilihan atau jasa secara konsisten di masa mendatang, sehingga menyebabkan pembelian berulang produk atau jasa dengan merek yang sama, meskipun ada pengaruh situasional dan upaya pemasaran yang dimiliki potensi untuk menyebabkan perilaku beralih ke produk atau jasa dengan merek yang lain.

Loyalitas pelanggan juga dapat didefinisikan sebagai komitmen pelanggan bertahan secara mendalam untuk berlangganan kembali atau melakukan pembelian ulang produk atau jasa terpilih secara konsisten di masa yang akan datang meskipun pengaruh situasi mempunyai potensi untuk menyebabkan perubahan perilaku (Hurryanti, 2005). Menurut Utomo, (2006) memberikan definisi mengenai loyalitas, yaitu derajat sejauhmana seorang pelanggan menunjukkan perilaku pembelian berulang dari suatu penyedia jasa, memiliki suatu kecenderungan sikap positif terhadap penyedia jasa, dan hanya mempertimbangkan untuk menggunakan penyedia jasa ini pada saat muncul kebutuhan untuk memakai jasa ini. Loyalitas pelanggan didefinisikan Taylor et al., (2004) sebagai pelanggan yang memiliki kemungkinan besar untuk membeli kembali suatu produk atau jasa yang disukai di masa mendatang, disamping pengaruh situasi dan usaha pemasar dalam merubah perilaku. Dengan kata lain pelanggan akan setia untuk melakukan pembelian ulang secara terusmenerus. (Adisetiawan, 2014)

\section{Hubungan Antar Variabel dan Pengembangan Hipotesis Pengaruh E-Service Quality Terhadap Customer Loyalty}

Hasil penelitian Kabir dan Didarul (2009) yang menghasilkan bahwa e-service quality adalah salah satu variabel yang memiliki pengaruh yang signifikan terhadap customer loyalty.Selanjutnya hasil penelitian Chen dan Chen (2011) juga menunjukkan bahwa e-service quality memiliki hubungan positif dengan customer loyalty.Lee et al., (2010) menyatakan, bahwa pelanggan yang puas menunjukkan loyalitas dan memberikan word-of-mouth yang positif, dengan demikian kepuasan pelanggan adalah anteseden loyalitas pelanggan dan menyebabkan pengaruh positif terhadap loyalitas (Lee et al., 2010). Sehingga hipotesis yang diajukan adalah:

\section{H1: E-Service Quality berpengaruh positif terhadap Customer Loyalty}

\section{Pengaruh E-Service Quality Terhadap Customer Satisfaction}

Kualitas layanan memiliki hubungan yang erat dengan kepuasan pelanggan.Kualitas layanan memberikan suatu dorongan kepada pelanggan untuk menjalin hubungan yang kuat dengan perusahaan (Tjiptono, 2007). Kualitas layanan online dikemukakan telah memberikan input yang penting bagi kepuasan pelanggan. Beberapa riset telah mengidentifikasi kepuasan disebabkan oleh kualitas layanan online yang diterima. Swain dan Wigand (2007) mengidentifikasikan dimensi E-Servqual berpengaruh positif dan signifikan terhadap kepuasan dan loyalitas. Hasil yang sama juga diperoleh Kassim dan Abdullah (2010) dalam penelitiannya, yaitu E-Servqual berpengaruh positif dan signifikan terhadap kepuasan pelanggan.

E-service quality memiliki hubungan yang erat dengan customer satisfaction. E-service quality memberikan suatu dorongan kepada pelanggan untuk menjalin ikatan hubungan yang kuat dengan perusahaan. Dalam jangka panjang ikatan seperti ini memungkinkan perusahaan untuk memahami dengan seksama harapan pelanggan serta kebutuhan pelanggan, dengan demikian perusahaan dapat meningkatkan customer satisfaction (Tjiptono 2001:54).E-service quality berkontribusi besar pada kepuasan, retensi pelanggan, word of mouthcommunication, pembelian ulang, loyalitas pelanggan (Tjiptono 2011:329). Parasuraman, Zeithaml dan Berry (1994) dalam Fatrio (2006) juga menyatakan bahwa semakin tinggi tingkat $e$-service quality yang 
dipersepsikan, semakin besar customer satisfaction. Berdasarkan beberapa penelitian tersebut maka hipotesis yang diajukan adalah:

\section{H2: E-Service Quality berpengaruh positif terhadap Customer Satisfaction}

\section{Pengaruh E-service Quality terhadap Customer loyalty melalui Customer Satisfaction}

E-service quality memiliki hubungan yang erat dengan customer satisfaction. E-service quality memberikan suatu dorongan kepada pelanggan untuk menjalin ikatan hubungan yang kuat dengan perusahaan sementara menurut Wendha et al.,2013, kepuasan konsumen memiliki pengaruh positif terhadap loyalitas konsumen. Customer satisfaction berkontribusi pada sejumlah aspek krusial, seperti terciptanya customer loyalty, meningkatnya reputasi perusahaan dan berkurangnya transaksi masa depan (Tjiptono, 2011:432). Lee et al., (2010) melakukan penelitian mereka dengan jasa industri pariwisata sebagai subyek eksperimental untuk mengeksplorasi hubungan antara customer satisfaction dan customer loyalty melalui transaksi online. Hasil penelitian menunjukkan customer satisfaction menyebabkan hubungan positif dengan customer loyalty.

Dalam layanan berbasis website tersebut banyak komponen-komponen penting didalamnya untuk mencapai kesuksesan dalam bisnis, salah satunya adalah kualitas pelayanan (E-Service Quality). Perusahaan yang memberikan e-service quality semakin tinggi kepada pelanggan maka akan menimbulkan customer satisfaction, dan dalam jangka waktu yang panjang tentunya akan menghasilkan customer loyalty. Sehingga hipotesis yang diajukan adalah:

\section{H3: E-Service Quality berpengaruh terhadap Customer Loyalty melalui Customer Satisfaction}

\section{METODE}

Jenis data pada penelitian ini adalah data kuantitatif yaitu data berupa angkayang diperoleh dari tanggapan atau penilaian responden setelah diberi skor (Durianto et al., 2001:19). Sumber data penelitian ini adalah data primer yang diperoleh dari pengisian kuesioner oleh pelanggan Buka Lapak Jambi yang terpilih menjadi responden.Data primer adalah data yang diperoleh dari individu atau perseorangan, seperti hasil wawancara atau hasil pengisian kuesioner (Sugiyono, 2004:74). Alat yang dipergunakan untuk mengumpulkan data dalam penelitian ini berupa daftar pertanyaan atau kuesioner yang diajukan pada responden sebagai pelanggan yang dijadikan sampel penelitian. Kuesioner yang telah diisi oleh responden tersebut kemudian diolah sehingga menghasilkan suatu data berbentuk kuantitatif yang dapat memberikan informasi bagi peneliti. Metode pengumpulan data adalah survei atau penelitian lapangan, yaitu dengan membagikan kuesioner kepada responden pelanggan Buka Lapak Indonesia untuk mendapatkan informasi, pendapat, dan tanggapan terhadap objek yang diteliti. Teknik analisis data dalam penelitian ini menggunakan Path Analysis. Path Analysis merupakan suatu teknik untuk menganalisis hubungan sebab akibat yang terjadi pada regresi berganda jika variabel bebasnya mempengaruhi variabel tergantung tidak hanya secara langsung tetapi juga secara tidak langsung. (Robert D Retherford: 1993).

Populasi menurut Sugiyono (2009), merupakan wilayah generalisasi yang terdiri atas, objek/subjek yang mempunyai kualitas dan karakteristik tertentu yang ditetapkan oleh peneliti untuk dipelajari dan kemudian ditarik kesimpulannya.Populasi dalam penelitian ini adalah Masyarakat Jambi yang sudah biasa melakukan online shop di Buka Lapak. Sedangkan sampel adalah bagian dari jumlah dan karakteristik yang dimiliki oleh populasi (Sugiyono,2009).Penarikansampeldilakukan dengan teknik nonprobability sampling yaitu dengan metode purposive sampling. Menurut Sugiyono (2009), nonprobability sampling dengan metode purposive sampling merupakan teknik penarikan sampel yang tidak memberikan peluang yang samabagi setiap unsur atau anggota populasi untuk dipilih menjadi sampel. Adapun kriteria untuk menentukan responden dalam penelitian ini diantaranya (1) masyarakat yang berdomisili di Jambi baik tetap maupun sementara; (2) Konsumen yang sudah dewasa atau lebih dari 18 tahun; dan (3) masyarakat yang pernah melakukan online shop di Buka Lapak minimal tiga kali.

\section{Definisi dan Operasional Variabel}

1. E-Service Quality $\left(\mathbf{X}_{1}\right)$, E-service quality dimana sebuah website dapat memfasilitasi proses belanja, pembelian dan sampai ke tahap pengiriman barang dan jasa secara efektif dan efisien, serta menyimpulkan bahwa konsumen harus bergantung sepenuhnya pada teknologi informasi dalam kegiatan e-commerce 
konsumen (Rolland dan Freeman, 2010). MenurutParasuraman et al., (2005) kualitas pelayanan elektronik (e-service quality) terdiri dari 4 dimensi sebagai berikut:

a. Reliability (kehandalan), yaitu fungsi situs yang benar dan ketepatan dari pelayanan yang dijanjikan kepada pelanggan (seperti: mempunyai stok barang yang cukup, mengantarkan barang kepada pelanggan tepat pada waktunya, informasi mengenai tagihan dan informasi mengenai barang atau jasa yang ditawarkan) (Chase, 2006). Indikator reliability adalah: website Buka Lapak secara cepat melalukan koreksi bila ada kesalahan; website Buka Lapak melayani pelanggan selalu konsisten; dan website Buka Lapakmemberikan pelayanan sesuai dengan keinginan pelanggan.

b. Responsiveness (ketanggapan), yaitu kecepatan layanan seperti pertanyaan konsumen, pencarian informasi, dan kecepatan navigasi, dimana layanan tersebut sangat penting bagi para customer (Lee \& Lin, 2005). Indikator responsiveness adalah: Transaksi yang pelanggan lakukan pada website Buka Lapak diproses dengan cepat; email konfirmasi pembelian barang dari Buka Lapak diterima dengan cepat; dan barang yang pelanggan beli di Buka Lapak diterima sesuai dengan waktu pengiriman yang dijanjikan.

c. Ease of use (kemudahan penggunaan), yaitu kemudahan yang dirasakan konsumen dalam berinteraksi dengan situs e-commerce sehingga mampu menerima informasi produk yang ia butuhkan (Wen et al., (2011)). Indikatorease of use adalah: Kemudahan akses dan penggunaan websiteBuka Lapak; Sistem pencarian barang, menu, dan navigasi yang terdapat pada website, buka Lapak mudah digunakan; dan pelanggan dapat menemukan hal-hal yang dibutuhkan pada website Buka Lapak dengan cepat.

d. Security (keamanan), yaitu berupa jaminan dari pihak websiteakan kerahasiaan data dari konsumen selama melakukan aktifitas belanja di website tersebut dan juga informasi kartu kredit/debit yang aman dan tidak dibocorkan ke pihak luar. Indikator privacy adalah: Website Buka Lapak melindungi data pribadi pelanggan; Website Buka Lapakmelindungi data terkait pembayaran pelanggan; dan Website Buka Lapak melindungidata pelanggan terkait kartu kredit, debit dan lain-lain.

\section{Customer Satisfaction (Z)}

Customer Satisfaction adalah persepsi senang atau kecewa seseorang yang berasal dari perbandingan antara kesannya terhadap kinerja (atau hasil) suatu produk dan harapan-harapannya (Danesh dan Nasab, 2001:298). Indikator yang digunakan dalam meneliti kepuasan konsumen adalah: Pelanggan senang dengan pelayanan yang diberikan oleh Buka Lapak; Pelanggan merasa puas terhadap produk yang dibeli di Buka Lapak; dan Kesesuaian harapan pelanggan terhadap kualitas belanja yang baik di Buka Lapak.

3. Customer Loyalty (Y)

Costumer Loyalty adalah komitmen pelanggan untuk membeli kembali atau melakukan pembelian secara berulang produk atau jasa yang lebih disukai di masa depan meskipun pengaruh situasi dan upaya pemasaran memiliki potensi untuk menyebabkan pelanggan beralih (Kotler dan Keller, 2009:138). Lima indikator konsumen yang loyal (Kotler 2002, Dewi et al., 2012) adalah: Pelanggan cenderung sering menggunakan jasa layanan Buka Lapak. Pelanggan bersedia kembali menggunakan jasa layanan dari Buka Lapak. Pelanggan tidak tertarik untuk beralih ke toko online yang lain. Pelanggan akan memberikan informasi yang positif kepada orang lain tentang Buka Lapak; dan Pelanggan akan merekomendasikan Buka Lapak kepada orang lain.

\section{Pengukuran Variabel}

Pengukuran variabel yang digunakan dalam penelitian ini menggunakan skala Likert.Menurut (Hermawan 2009:132), Skala Likert merupakan skala yang mengukur kesetujuan atau ketidaksetujuan seseorang terhadap serangakaian pernyataan berkaitan dengan keyakinan atau perilaku mengenai suatu obyek tertentu.Metode pengukuran variabel yang digunakan penelitian ini adalah skala likert 5 poin, dimana skala ini mempunyai skala 1 sampai dengan 5. Bentuk penilaian jawaban responden kuesioner menggunakan pembobotan sebagai berikut (Indriantoro dan Supomo, 1999:124): Sangat Tidak Setuju (STS) diberi skor 1; Tidak Setuju (TS) diberi skor 2; Netral (N) diberi skor 3; Setuju (S) diberi skor 4; Sangat Setuju (SS) diberi skor 5

\section{HASIL}


Penelitian ini dilakukan dengan menyebarkan quisioner kepada 100 responden terdiri dari Pria sebanyak 40 orang dan wanita sebanyak 60 orang. Ada pun pekerjaan responden terdiri dari: pelajar sebanyak $26 \%$, pegawai swasta sebanyak 25\%, wiraswasta 17\%, Pegawai Negeri Sipil 17\%, Profesional 5\%, Ibu rumah tangga 6\%, dan lain-lain 5\%. Sedangkan jumlah penghasilan responden dalam 1 bulan yaitu: dibawah 2 juta sebanyak 29\%, 2 juta hingga 4 juta sebanyak 24\%, 4 juta hingga 6 juta sebanyak $25 \%$ dan responden dengan penghasilan di atas 6 juta sebanyak 13\%. Frekwensi responden berbelanja di Buka Lapak dalam 1 tahun terdiri dari: 1 sampai 1 kali sebanyak 40\%, 3 hingga 4 kali sebanyak 31\% dan responden yang lebih dari 4 kali dalam setahun sebanyak $29 \%$.

Tabel 1.

Descriptive Statistics

\begin{tabular}{|c|c|c|c|c|c|}
\hline & $\mathrm{N}$ & Minimum & Maximum & Mean & Std. Deviation \\
\hline$X$ & 100 & 1.73 & 4.00 & 3.3253 & .52879 \\
\hline $\mathrm{Z}$ & 100 & 2.67 & 5.00 & 4.1800 & 67240 \\
\hline $\mathrm{Y}$ & 100 & 1.80 & 5.00 & 3.9780 & .72077 \\
\hline Valid N (listwise) & 100 & & & & \\
\hline
\end{tabular}

Sumber: data olahan

Berdasarkan Tabel 1 diatas dapat dijelaskan bahwa jumlah data untuk masing-masing variabel sebanyak 100 data. Variabel X (E-Service Quality) memiliki nilai minimum 1,73 dan maksimum 4 dengan standar deviasi 0,5 dan rata-rata 3,3. Hal ini menunjukkan bahwa responden menjawab setuju dan beberapa responden menjawab tidak setuju terhadap layanan E-service yang dilakukan oleh Buka Lapak. Meskipun demikian rata-rata responden memberi respon yang baik yang ditunjukkan dengan rata-rata jawaban sebesar 3.3.. Variabel Z (Customer satisfaction) memiliki nilai minimum 2,67 dan maksimum 5 dengan standar deviasi 0,67 dan rata-rata 4,1. Secara umum responden menyatakan puas dengan layanan dan produk dari Buka Lapak yang ditunjukkan dengan nilai rata-rata jawaban sebesar 4,1. Variabel Y(Customer loyalty)memiliki nilai minimum 1,8 dan maksimum 5, standar deviasi 0,7 dan rata-rata 3,9. Hal ini menunjukkan bahwa loyalitas konsumen pada Buka Lapak cukup baik meskipun beberapa responden menyatakan tidak loyal (memberi nilai 1) akan tetapi sebagian besar konsumen menyatakan loyal yang ditunjukkan dengan jawaban dengan nilai lebih besar dari 3.

\section{Pengujian regresi}

Hasil analisis Persamaan 1

Hasil pengolahan data dapat ditunjukkan seperti pada tabel berikut:

Tabel 2.

Model Summary persamaan 1

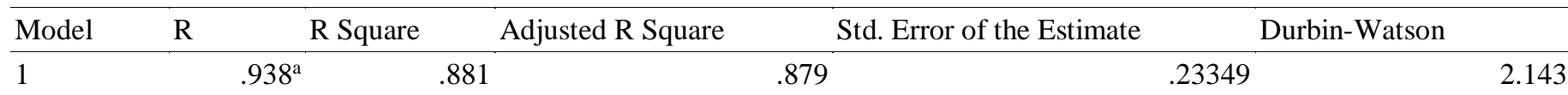

Sumber: data olahan

Tabel 3.

ANOVA persamaan 1

\begin{tabular}{lllllll}
\hline Model & & Sum of Squares & df & Mean Square & F & Sig. \\
\hline 1 & Regression & 39.417 & 1 & 39.417 & 723.039 & $.000^{\mathrm{a}}$ \\
& Residual & 5.343 & 98 & .055 & & \\
& Total & 44.760 & 99 & & & \\
\hline
\end{tabular}

Sumber: data olahan 
Tabel 4.

Coefficients persamaan 1

\begin{tabular}{|c|c|c|c|c|c|c|c|c|c|c|c|c|}
\hline \multirow{2}{*}{\multicolumn{2}{|c|}{ Model }} & \multirow[b]{2}{*}{$\mathrm{B}$} & \multicolumn{2}{|c|}{$\begin{array}{l}\text { Unstandardized } \\
\text { Coefficients }\end{array}$} & \multicolumn{2}{|c|}{$\begin{array}{l}\text { Standardized } \\
\text { Coefficients }\end{array}$} & \multirow[t]{2}{*}{$\mathrm{t}$} & \multirow[t]{2}{*}{ Sig. } & \multicolumn{2}{|c|}{ 95\% Confidence Interval for B } & \multicolumn{2}{|c|}{$\begin{array}{c}\text { Collinearity } \\
\text { Statistics }\end{array}$} \\
\hline & & & & Std. Error & Beta & & & & Lower Bound & Upper Bound & Tolerance & VIF \\
\hline \multirow[t]{2}{*}{1} & (Constant) & & .212 & .149 & & & 1.419 & .159 & -.085 & .508 & & \\
\hline & $X$ & & 1.19 & .044 & & .938 & 26.88 & .000 & 1.105 & 1.281 & 1.000 & 1.000 \\
\hline
\end{tabular}

Sumber: data olahan

Tabel 3 di atas dapat dibentuk persamaan sebagai berikut:

$\mathrm{Z}=0.212+1.19 \mathrm{X}$

Prob. Sig $\quad(0,159) \quad(0,000) \quad R^{2}=0.881 \quad F=723,09 \quad$ Sig $=0.000$

1. Uji Pengaruh secara bersama-sama (Uji F)

Variabel dependen $\mathrm{X}$ terhadap $\mathrm{Z}$ dapat dijelaskan berdasarkan $\mathrm{R}^{2}$ yang dihasilkan dari persamaan regresi. Berdasarkan tabel dibawah ini diperoleh hasil sebesar 0,881 atau $88,1 \%$. Yang artinya adalah variabel $\mathrm{X}$ mampu menjelaskan perubahan variabel $\mathrm{Z}$ sebesar $88,1 \%$, sedangkan sisanya dijelaskan oleh variabel lain yang tidak diteliti dapam penelitian ini. Berdasarkan uji $\mathrm{F}$ diperoleh nilai $\mathrm{F}$ sebesar 723,09 dengan probabilitas siginifikansi 0,000. Hal ini menunjukkan bahwa model yang di bangun fit untuk digunakan melakukan analisa dan prediksi.

2. Uji pengaruh secara parsial (Uji t)

Berdasarkan persamaan di atas dapat diketahui bahwa variabel X menghasilkan koefsien sebasar 1,19 yang berarti bahwa setiap terjadi kenaikan nilai Xsebesar 1 satuan akan menyebabkan penurunan nilai Zsebesar 1,19 satuan. Dengan nilai probabilitas 0,000 yang lebih kecil dari $\alpha=0,05$ maka pengaruh $\mathrm{X}$ terhadap Z signifikan.

Hasil analisis Persamaan 2

Hasil pengolahan data dapat ditunjukkan seperti pada tabel berikut:

Tabel 5.

Model Summary persamaan 2

\begin{tabular}{|l|l|l|ll|l|}
\hline Model & R & R Square & Adjusted R Square & Std. Error of the Estimate & Durbin-Watson \\
\hline 1 & $.887^{\mathrm{a}}$ & .787 & .783 & .33609 & 1.714 \\
\hline
\end{tabular}

Sumber: data olahan

Tabel 5.

ANOVA persamaan 2

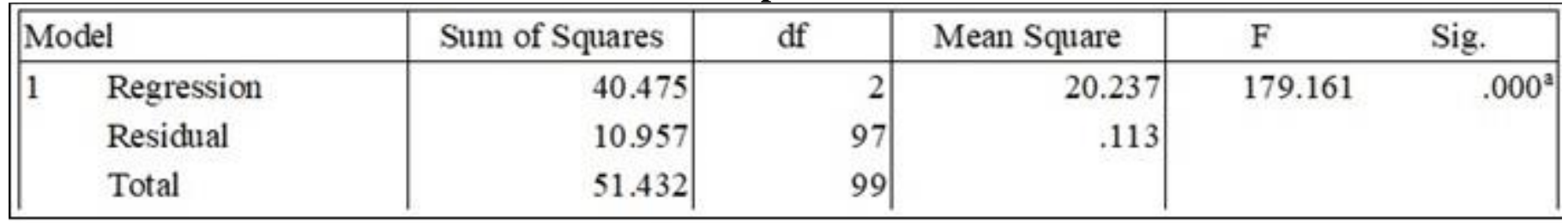

Sumber: data olahan

Tabel 6.

Coefficients

\begin{tabular}{|c|c|c|c|c|c|c|c|c|c|c|}
\hline \multirow{2}{*}{\multicolumn{2}{|c|}{ |Model }} & \multicolumn{2}{|c|}{ Unstandardized Coefficients } & \multirow{2}{*}{\begin{tabular}{|c|} 
Standardized Coefficients \\
Beta
\end{tabular}} & \multirow{3}{*}{$\begin{array}{c}\mathrm{t} \\
-.377\end{array}$} & \multirow[b]{2}{*}{ Sig. } & \multicolumn{2}{|c|}{$95 \%$ Confidence Interval for B } & \multicolumn{2}{|c|}{ Collinearity Statistics } \\
\hline & & B & Std. Error & & & & Lower Bound & Upper Bound & Tolerance & VIF \\
\hline $\mid 1$ & (Constant) & -.082 & .217 & & & .707 & -.513 & .349 & & \\
\hline & $\mathrm{x}$ & .859 & .185 & .630 & 4.644 & .000 & .492 & 1.226 & .119 & 8.378 \\
\hline & $\mathrm{Z}$ & 288 & .145 & .269 & 1.982 & .050 & .000 & .577 & .119 & 8.378 \\
\hline
\end{tabular}

Sumber: data olahan 
Berdasarkan tabel 6 di atas maka diperoleh persamaan sebagai berikut:

$\mathrm{Y}=-0.082+0.8599 \mathrm{X}+0.288 \mathrm{Z}$

$\begin{array}{llllll}\text { Prob. Sig } & (0,707) & (0,000) & (0.050) & R^{2}=0.787 & F=179,16\end{array}$

Uji Pengaruh secara bersama-sama (Uji F)

Variabel dependen $\mathrm{Xdan} \mathrm{Z}$ terhadap $\mathrm{Y}$ dapat dijelaskan berdasarkan $\mathrm{R}^{2}$ yang dihasilkan dari persamaan regresi. Berdasarkan tabel dibawah ini diperoleh hasil sebesar 0,787 atau 78,7\%. Yang artinya adalah variabel $\mathrm{X}$ dan Z mampu menjelaskan perubahan variabel Y sebesar 78,7\%, sedangkan sisanya dijelaskan oleh variabel lain yang tidak diteliti dapam penelitian ini. Berdasarkan uji $\mathrm{F}$ diperoleh nilai $\mathrm{F}$ sebesar 179,16 dengan probabilitas siginifikansi 0,000. Hal ini menunjukkan bahwa model yang di bangun fit untuk digunakan melakukan analisa dan prediksi.

\section{Uji pengaruh secara parsial (Uji t)}

Berdasarkan persamaan di atas dapat diketahui bahwa variabel X menghasilkan koefsien sebasar 0,8599 yang berarti bahwa setiap terjadi kenaikan nilai Xsebesar 1 satuan akan menyebabkan kenaikan nilai Y sebesar 0,8599 satuan. Dengan nilai probabilitas 0,000 yang lebih kecil dari $\alpha=0,05$ maka pengaruh X terhadap Y signifikan. Sedangkan pengaruh Z terhadap Y ditunjukkan dengan koefisien sebesar 0,288 yang artinya setiap kenaikan variabel $Z$ akan menyebabkan kenaikan variabel Y sebesar 0,288. Dengan nilai probabilitas sebesar 0,05 yang sama dengan $\alpha=0,05$ maka dapat dinyatakan bahwa variabel $\mathrm{Z}$ mempengaruhi variabel $\mathrm{Y}$ secara siginifikan.

\section{Uji Hipotesis}

Penelitian ini ingin menguji 3 hipotesis yaitu:

H1: E-Service Quality berpengaruh positif terhadap Customer Loyalty

H2: E-Service Quality berpengaruh positif terhadap Customer Satisfaction

H3: E-Service Quality berpengaruh terhadap Customer Loyalty melalui

Customer Satisfaction

Hasil pengujian hipotesis dapat ditunjukkan pada tabel berikut ini:

Tabel 7.

Hasil Uji Hipotesis

\begin{tabular}{lllll}
\hline & Hipotesis & Koef. Reg & Prob. Sig & Keseimpulan \\
\hline E service quality $\rightarrow$ Customer loyalty & + & 0,8599 & 0,000 & H1. diterima \\
E service quality $\rightarrow$ Customer Satisfaction & + & 1,19 & 0,000 & H2 diterima \\
E service quality $\rightarrow$ Customer satisfaction $\rightarrow$ & + & 1,19 & 0.000 & \\
Customer loyalty & + & 0,288 & 0,050 & H3 diterima \\
\hline
\end{tabular}

Berdasarkan tabel 7 diatas maka hipotesis 1 yang menyatakan bahwa e service quality berpengaruh positif terhadap customer loyalty dapat diterima. Hasil ini mendukung penelitian yang dilakukan oleh Kabir dan Didarul (2009), Chen dan Chen (2011) dan Lee et al., (2010) yang menyatakan, bahwa pelanggan yang puas menunjukkan loyalitas dan memberikan word-of-mouth yang positif, dengan demikian kepuasan pelanggan adalah anteseden loyalitas pelanggan dan menyebabkan pengaruh positif terhadap loyalitas. Hasil penelitian juga menunjukkan bahwa hipotesis 2 yang menyatakan bahwa e service quality berpengaruh positif terhadap customer satisfaction diterima. Hasil ini menunjukkan bahwa Kualitas layanan memiliki hubungan yang erat dengan kepuasan pelanggan sesuai dengan hasil penelitian yang dilakukan oleh Swain dan Wigand (2007) dan Kassim dan Abdullah (2010). Selain hipotesis 1 dan 2, dalam penelitian ini menunjukkan hasil bahwa hipotesis 3 yang menyatakan bahwa e service quality berpengaruh terhadap customer loyalty melalui customer satisfaction juga diterima. Ini berarti perusahaan yang memberikan e-service qualityyang tinggi kepada pelanggan akan menimbulkan customer satisfaction, dan dalam jangka waktu yang panjang akan menghasilkan customer loyalty. 


\section{SIMPULAN}

Analisis diatas dapat disimpulkan sebagai berikut:

1. E-service quality berpengaruh langsung terhadap customer loyalty konsumen Buka Lapak Indonesia.

2. E-service quality berpengaruh positif terhadap customer satisfaction konsumen Buka Lapak Indonesia.

3. E-service quality berpengaruh terhadap customer loyalty melalui customer satisfaction konsumen Buka Lapak Indonesia.

\section{DAFTAR PUSTAKA}

Adisetiawan, R., 2013, Kajian Persepsi Pemilik Usaha Kecil Dan Menengah (UKM) Terhadap Laporan Keuangan, Jurnal Ilmiah Universitas Batanghari, 13(4), 162-173

Adisetiawan, R., 2014, Performance Mahasiswa Fakultas Ekonomi Universitas Batanghari Jambi, Jurnal Ilmiah Universitas Batanghari, 14(3), 1-10

Anderson, R. E., \&Srinivasan, S. S. (2003). E-satisfaction ande--loyalty: A contingency framework. Psychology \& marketing, 20(2),123-138.

Anderson, R. E., \& Swaminathan, S. (2011). Customer satisfaction and loyalty in e-markets: A PLS path modeling approach. The Journal of Marketing Theory and Practice, 19(2),221-234.

Barnes, James G. (2003). Secret Of Customer Relationship Manangement. Alih bahasa. Andreas Winardi. Yogyakarta: Penerbit Andi.

Hair, J.F. et al. (2010) Multivariate Data Analysis A Global Perspective. Seven Edition. Pearson.

Kim,HyejeongandNiehm,L.S.(2009). “TheImpactOfWebsiteQualityOn Information Quality, Value, And Loyalty Intentions In Apparel Retailing”. Journal Of InteractiveMarketing.

Kotler, Philip dan Keller, K.L. (2006). Manajemen Pemasaran. Jakarta: Ghalia Indonesia.

Parasuraman, A., Zeithaml, V. A., \& Berry, L. L. (1985).A conceptual model of service quality and its implications for future research.Journal of marketing,49(4)

Sadeh, Ehsan. et al. (2012). "The Effect of Website Quality Dimensions on Customer Satisfaction in E-Retailing System”. Middle-East Journal of Scientific Research.

Siagian, Hotlan dan Cahyono, Edwin.(2014). "Analisis Website Quality, Trust, dan Loyalty Pelanggan Online Shop".Jurnal Manajemen Pemasaran.

Sugiyono. (2005). Metode Penelitian Administrasi. Bandung: Alfabeta

Tjiptono, Fandy dan Gregorius Chandra. (2005). "Service, Quality \& Satisfaction”. Yogyakarta: Andi.

Zeithaml, V. A., Parasuraman, A., \& Malhotra, A. (2002). Service quality delivery through web sites: a critical review of extant knowledge. Journal of the academy of marketing science, 30(4), 362-375. 